\title{
Honey bees do not displace foraging bumble bees on nectar-rich artificial flowers
}

\author{
Jay M. IWASAKI ${ }^{1,2}$, Barbara I. P. BARRATT ${ }^{1,3}$, Jennifer M. JANDT ${ }^{2}$, \\ Timothy W. D. JOwetT ${ }^{4}$, Janice M. LORD ${ }^{1}$, Alison R. MERCER ${ }^{2}$, \\ Katharine J. M. DICKINSON ${ }^{1}$
}

\author{
${ }^{1}$ Department of Botany, University of Otago, P O Box 56, 479 Great King St., Dunedin 9010, New Zealand \\ ${ }^{2}$ Department of Zoology, University of Otago, P O Box 56, 479 Great King St., Dunedin 9010, New Zealand \\ ${ }^{3}$ AgResearch Limited, Invermay Agricultural Centre, Puddle Alley, Private Bag 50034, Mosgiel 9010, New Zealand \\ ${ }^{4}$ Department of Mathematics and Statistics, University of Otago, P O Box 56, 479 Great King St., Dunedin 9010, New \\ Zealand
}

Received 24 January 2019 - Revised 28 July 2019 - Accepted 10 September 2019

\begin{abstract}
In an enclosed glasshouse with sucrose provisioned artificial flowers, we observed nectar-foraging bumble bees and honey bees under several resource conditions to determine potential for displacement. Different responses were displayed for varying resource treatments. Overall, bumble bees did not show reduced foraging in the presence of honey bees. When resources were reduced, bumble bees did not change their foraging behavior, whereas honey bees responded by decreasing their visitation rate. When a food resource of higher quality was introduced, bumble bee foragers shifted their foraging effort to the high-quality resources, whereas honey bees continued to forage on the lower quality resources they had been foraging on. We discuss these results by considering how the individual strategy of bumble bees compared with the colony-based strategy of honey bees may explain observed differences and highlight the potential advantages of each strategy in the natural environment.
\end{abstract}

\section{honey bees / bumble bees / artificial flowers / foraging / competition}

\section{INTRODUCTION}

Bees may partition resources via differences in nesting habitat, seasonal timing of emergence, pollen preferences, and foraging ranges (Westphal et al. 2006). How honey bees in particular compete with other pollinators for resources has been a topic of ongoing research (Donovan 1980; Roubik et al. 1986; Huryn 1997; Roubik and Wolda 2001; Goulson 2003a; Paini 2004;

Electronic supplementary material The online version of this article (https://doi.org/10.1007/s13592-019-00690-z) contains supplementary material, which is available to authorized users.

Corresponding author: J. Iwasaki, jay.iwasaki@adelaide.edu.au

Manuscript editor: Monique Gauthier
Paini and Roberts 2005; Howlett and Donovan 2010). As generalists, honey bees may outcompete other bee species for access to floral resources due to the large number and range of plant species honey bees can visit (Huryn 1997), and their ability to rapidly recruit nestmates to a high-quality resource which can result in high densities of foragers (Seeley et al. 1991; von Frisch 1967). Further, there is evidence that the presence or increased population density of honey bees may have a negative impact on bumble bees and solitary bees (Paini 2004; Goulson 2003a; Huryn 1997; Thomson 2016; Paini and Roberts 2005). However, bumble bees are also generalist foragers, and there is evidence that they may outcompete other bees as well. After being introduced to a new region, Bombus terrestris, for example, has been 
shown to outcompete megachilid bees in Tasmania (Hingston and McQuillan 1999) and native bumble bees in Japan (Inoue et al. 2008). On some resources, such as lavender that requires the longer tongue of the bumble bee to access the nectar, bumble bees can even outcompete honey bees for resources (Balfour et al. 2015).

Competition among bees for resources can occur indirectly, through exploitative competition when resources are depleted (Schaffer et al. 1983, 1979; Roubik et al. 1986; Dupont et al. 2004), or directly, through interference competition where bees are deterred from foraging due to the presence of other bee species (Roubik 1978; Eickwort and Ginsberg 1980). When foraging, honey bees generally do not show aggressive interference competition (Goulson 2003a). However, changes in bumble bee foraging behavior in response to the presence of honey bees have been noted in field experiments through temporal displacement, although the strength of the response can vary between bumble bee species, based on resource preferences and foraging range (Walther-Hellwig et al. 2006). There is also evidence that honey bee presence contributes to the development of smaller average sizes of worker bumble bees in colonies foraging in the same area (Goulson and Sparrow 2009). The size of worker bumble bees corresponds to their energetic efficiency and foraging ability with consequences on the potential fitness of the colony (Heinrich 1976; Spaethe and Weidenmüller 2002; Dornhaus and Couvillon 2010). Thomson (2004) examined the reproductive success of bumble bees in the presence of honey bees, and reported a reduction in gyne (potential new queens) numbers, gyne:worker ratio, mean gyne size, and male sightings with increasing proximity to honey bee hives.

Here we determine whether honey bees and bumble bees compete in a nectar-rich, glasshouse environment. We examine whether bumble bee foraging was constrained by the presence of honey bees, and to what extent resource availability and quality influenced foraging patterns. Controlled environment studies on honey bee and bumble bee interactions are rarely reported and can be difficult to conduct. To our knowledge, this type, and scale, of study comparing foraging behaviors has not been conducted successfully before. Generally, honey bees are not as conducive to glasshouse foraging as bumble bees, the latter being extensively used for glasshouse crop pollination because of their ability to forage naturally in confined conditions (Goulson 2010). Based on previous research, we predicted that bumble bee foraging would be influenced by the presence of honey bees (Walther-Hellwig et al. 2006). Moreover, we hypothesized that if honey bees displace bumble bees while foraging, then as resource availability decreased or quality increased, honey bees would monopolize or physically displace bumble bees from these resources. While honey bees are important pollinators, alternative pollinators are increasingly recognized; thus, the potential negative impacts on key crop pollinators such as bumble bees are of particular significance (Garibaldi et al. 2017).

\section{MATERIALS AND METHODS}

The study was carried out from March to April 2014 at Invermay Agricultural Centre, Mosgiel, New Zealand. We purchased six bumble bee colonies (Bombus terrestris , BioBees Ltd., Hastings, New Zealand) for each experiment, and one small honey bee hive (Apis mellifera, Rent-A-Hive, Mosgiel, New Zealand) that was used across both experiments. After the included syrup supplements were removed, colonies were left in their original packaging and placed into a large bisected translucent polycarbonate glasshouse $(13 \times 42 \mathrm{~m}$ total, $13 \times 21 \mathrm{~m}$ dimensions in each section). Temperature $\left({ }^{\circ} \mathrm{C}\right)$ and natural light levels (lux) were recorded every five minutes on the foraging platforms in the glasshouse by two Onset UA002-08 HOBO dataloggers (Bourne, MA, USA).

Pilot trials prior to the experiment were conducted to determine the number of flowers that small honey bee colonies and bumble bee colonies would use. A small hive utilized less than $50 \%$ of the artificial flowers, whereas four bumble bee colonies (with $\sim 50$ workers in each) utilized about $10 \%$ of the flowers. On one side (hereafter $\mathrm{HB}+\mathrm{BB}$ ), we placed one honey bee nucleus hive (approx. 4000 bees) and two bumble bee colonies (approx. 60-80 bees/colony). On the other side (hereafter BB), we placed four bumble bee 
colonies (estimated to be approx. 40-60 bees/colony). Hives ordered from BioBees varied in size; so to balance bee densities, estimates of bee workers were obtained by opening boxes and counting the number of active bees after a oneminute period (exposure to light will bring the bees out of the cotton matrix).

Artificial flowers and their arrangement followed the protocols outlined in Rogers et al. (2013) with slight modifications. Nectar wells were constructed from 1.7-mL Eppendorf micro centrifuge tubes with caps removed. A cotton wick wetted with sucrose solution was first inserted to the $0.5-\mathrm{mL}$ mark on the Eppendorf tube to prolong nectar availability by reducing evaporation. Petal shapes were punched from blue plastic sheets to create landing platforms. The tubes were then inserted through a central hole in the plastic sheet to create a flower. Four flowers were grouped in an array on a $10 \times 10 \mathrm{~cm}$ polycarbonate square (Figure 1).

Sixteen flower arrays were spaced into a $1 \times$ $1 \mathrm{~m}$ square grid giving a total of 64 flowers. The flower arrays were placed on a table covered in green "astro-turf” fabric (Figure 1b, c). Above each of the four flower grids $(1.5 \mathrm{~m}$, enough to cover the field of view), we mounted a Bushnell Trophy Cam HD trail camera (Overland Park, KS, USA). Analyses of bee visitation frequencies were carried out using photographs taken at 15-min intervals between 9 a.m. and 5 p.m. to allow changes in forager composition. For each image, we counted the number of honey bees or bumble bees in contact with a flower. From each image, the counts of each bee species were analyzed as data points.

Native New Zealand plants (Pittosporum sp., Pseudopanax crassifolius, Pseudowintera colorata) without flowers were placed at each side of the glasshouse to provide structure and landmarks for the foraging bees.

\subsection{Experiment 1: Reduced resource quantity}

To determine how resource quantity affects foraging behavior, we monitored foraging on full and reduced flower numbers in the arrays (Figure 1b, c), with a constant sugar concentration. Nectar wells were filled ( $1.5 \mathrm{~mL})$ daily with 2-M (685 g/L) sucrose solution with $25 \mathrm{~g} / \mathrm{L}$ of honey for scent. To train bees to the flowers and to collect baseline foraging data without competition on the HB+BB side, honey bees and bumble bees foraged alone for two to three days during a pre-trial period on the full number of 16 arrays (64 flowers). On the BB side, bumble bees were also restrained to foraging on the same days that bumble bees foraged on the $\mathrm{HB}+\mathrm{BB}$ side. All bees were all allowed to forage for the next three days (days 1-3). On day 4, we reduced the number of arrays to eight ( 32 flowers) and monitored foraging behavior of all bees for four days (days 4-7). We then reinstated the 16 foraging arrays (64 flowers) and all bees were monitored for an additional four days (days 8-11).

At the end of experiment 1, the honey bee hive was removed from the glasshouse and bees were allowed to forage naturally outside of the glasshouse for 12 days between experiments. New bumble bee colonies were used for each experiment. Bumble bee colonies used in experiment 1 were killed by freezing. Six additional bumble bee colonies were purchased for use in experiment 2.

\subsection{Experiment 2: Increased resource quality}

To determine how resource quality and quantity affect foraging behavior, we varied sucrose concentration and number of flowers. The glasshouse was arranged in the same way as for experiment 1 but with different resource treatments on offer. Following a similar pre-trial period, all bees foraged freely for two days (days 1-2) on the full number of 16 flower arrays with all flowers filled with $\sim 1.5 \mathrm{~mL}$ of a 2-M sucrose solution. From day 3, one table array was filled with a 4-M sucrose solution (1370 g sucrose/L), while the other was refilled with the 2-M solution. On day 6 , we removed half of the flowers (an equal number of both concentrations) and monitored foraging behavior for the following three days. On day 9, we reinstated the 16 arrays (half 2-M, half 4-M sucrose) and monitored bees for a further two days. On day 11, all flowers contained 2-M sucrose, and bee foraging was monitored for an additional three days to day 14 . 

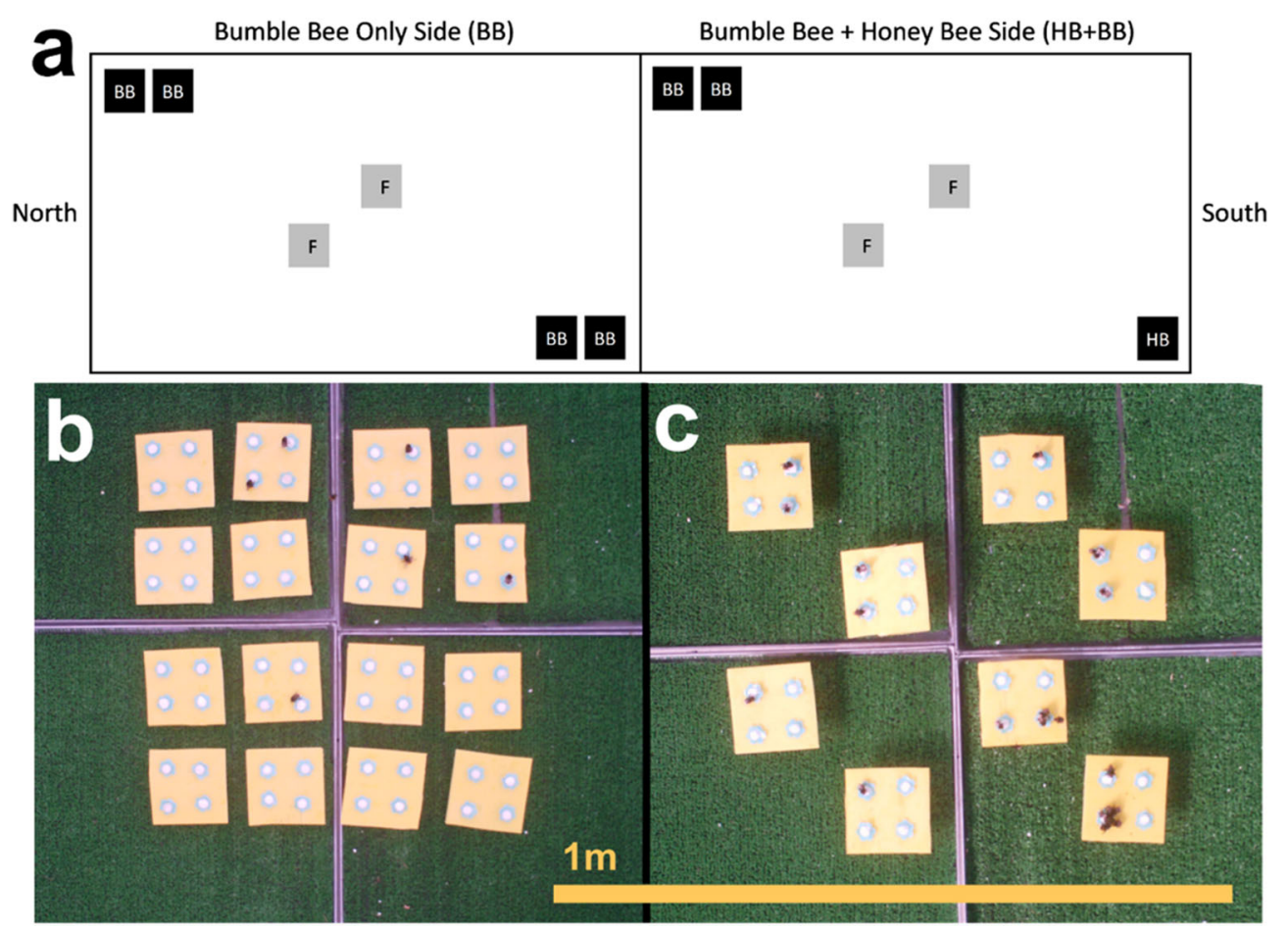

Figure 1. a The experimental glasshouse (north-south orientation) and artificial flower arrangements in the two halves of the glasshouse showing partition into a bumble bee-only side (BB, left) and honey bee/bumble bee side ( $\mathrm{HB}+\mathrm{BB}$, right) with hives (Bombus blue; Apis yellow). Foraging tables ( $\mathrm{F}$, gray squares) were located $10.3 \mathrm{~m}$ equidistant from the hives with foraging arrays placed in the center of the tables ( $4 \mathrm{~m}$ from each other). $\mathbf{b}$ Overhead photos of full flower array (16 arrays with 64 flowers) and $\mathbf{c}$ half flower array ( 8 arrays with 32 flowers).

\subsection{Statistical analyses}

All analyses were performed using $\mathrm{R}$ version 3.2.3 (Anon 2013). Generalized additive mixed models (GAMM; gamm function, mgcv package) were used to compare abiotic conditions between sides (temperature, light), with date and time as random factors (Wood 2011). Generalized linear mixed models (GLMM) with random effects (glmer function) from the lme 4 package and GLMM with random effects using penalized quasi-likelihood ( $\mathrm{glmm} P Q L$ function) from the MASS package were used (Bates et al. 2013). Glmer and GlmmPQL models were used to analyze the relationship between either honey bee or bumble bee foraging counts (dependent variables) and relevant explanatory variables (glasshouse side, temperature, light levels, fixed treatments, resource quality, honey bee numbers), with date and time as random factors. Welch's $t$ tests were used to analyze counts between treatments, as the means of the two samples were of unequal variance.

Models run were specified as Poisson distributed or quasi-Poisson in order to account for overdispersion. GlmmPQL models were run because they can allow for overdispersion by the implementation of quasi-likelihood estimation (Wedderburn 1974). Glmer uses maximum likelihood and/or restricted maximum likelihood and is not able to allow for overdispersion. Multiple models were compared using the Akaike Information Criterion (AIC) to justify interactive terms and identify the best fitting models. Models were checked for overdispersion using Pearson goodness of fit tests.

Temperature and light were highly correlated and were modeled separately to avoid errors associated with multicollinearity. $P$ values used were taken from models that included temperature 
as a predictor value on the assumption that temperature is a more relevant biological factor (significance did not change, but $P$ values varied).

\section{RESULTS}

Light (lux) and temperature $\left({ }^{\circ} \mathrm{C}\right)$ on the two sides of the glasshouse were similar over the trial period for each of the experiments (experiment $1, P=0.269$; experiment $2, P=$ 0.159 , GAMM, Table SI, SII). Both bee species had similar activity times that correlated with the increase in light and temperature peaking between 10.15 a.m. and 12.15 p.m., with a gradual decline after peak times.

Bumble bee foraging was not affected by the presence of honey bees (Figure 2), even though honey bee foragers outnumbered bumble bee foragers for both experiments. In addition, when foraging together, honey bee and bumble bee counts were significantly positively correlated during each experiment (all $P<0.001$, GLMM PQL, Table SIII $\mathrm{SVI}$ ), that is, bumble bees were not displaced by honey bees during either experiment, but instead as honey bee foraging increased, so did bumble bee foraging. Notably, the proportion of flowers utilized during each experiment was relatively low (experiment $1 \mu \pm$ $\mathrm{SD}$ : BB $0.10 \pm 0.05, \mathrm{HB}+\mathrm{BB} 0.22 \pm 0.12$, experiment 2: $\mathrm{BB} 0.10 \pm 0.06, \mathrm{HB}+\mathrm{BB} 0.19 \pm$ 0.12 ).

\subsection{Experiment 1: Reduced resource quantity}

When flower availability was reduced, bumble bee foraging decreased $(P=0.03)$ on both glasshouse sides (GLMM PQL, Table I, Table SIIIa). Although there were estimated to be more bumble bees on the $\mathrm{HB}+\mathrm{BB}$ side than the $\mathrm{BB}$ side, the proportion of change in forager numbers for both sides was not significantly different ( $P=0.86$, GLMM PQL, Table SIIIa). Similarly, when flower availability was reduced by half, there were significantly fewer ( $P=0.001$, GLMM PQL, HB+BB side only, Table SIVa) foraging honey bees compared with the full flower treatment.

\subsection{Experiment 2: Increased resource quality}

Bumble bee foragers were found significantly more often on the high concentration (4-M) sucrose solution on both the $\mathrm{BB}$ and $\mathrm{HB}+\mathrm{BB}$ side $(P=0.002$, GLMM PQL, Figure 3a, Table I, SVa). Honey bees, by contrast, did not show an increase in foraging counts on the higher quality resources presented to them $(P=0.27$, GLMM PQL, Fig. 3b, Table SVIa).

\section{DISCUSSION}

Honey bees and bumble bees are both generalist pollinators that have the potential to compete for floral resources (Thomson 2004; Thomson 2006; Rogers et al. 2013; Goulson and Sparrow 2009). Here we show that bumble bee foraging was not affected by the presence of honey bees in a nectar-rich environment, but their foraging effort was more reflective of the quality and quantity of available resources. When resource availability was reduced by half, both honey bees and bumble bees decreased their foraging effort. However, only bumble bees showed a clear preference for the resource quality associated with the higher sucrose concentrations presented to them (4M).

Despite differences in overall nectar availability, our results in a controlled glasshouse environment are similar to field (Goulson 2003b) and other confined studies (Rogers et al. 2013) which have shown little indication of direct competition between honey bee and bumble bees. We saw no evidence that bumble bee foragers were being displaced by honey bee foragers. Instead, we show that when honey bee forager counts increased, bumble bee counts also increased. In previous experiments, bumble bee foraging behavior has been found to be altered more following interactions with honey bees than vice versa. Rogers et al. (2013) found that foraging bumble bees were more likely to be displaced from a flower following an encounter by a honey bee than by a conspecific. Honey bees by contrast showed similar responses to bumble bees or conspecifics. Occupancy of flowers has been shown to negatively influence foraging abundance of other bees as well, particularly between honey 


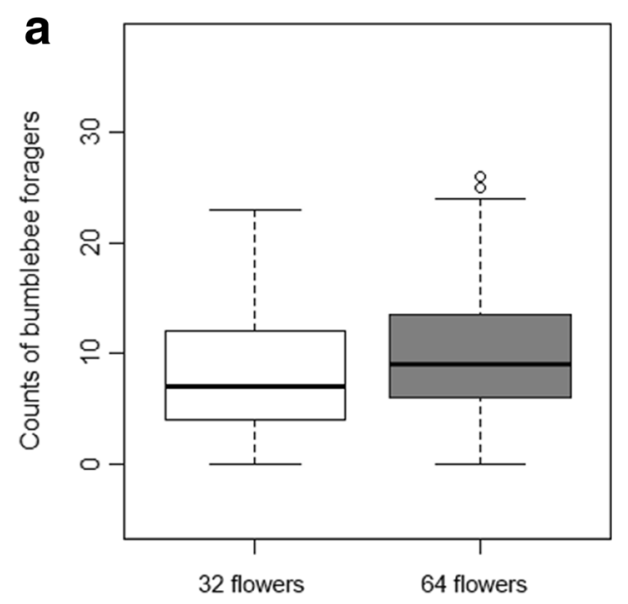

BB control side

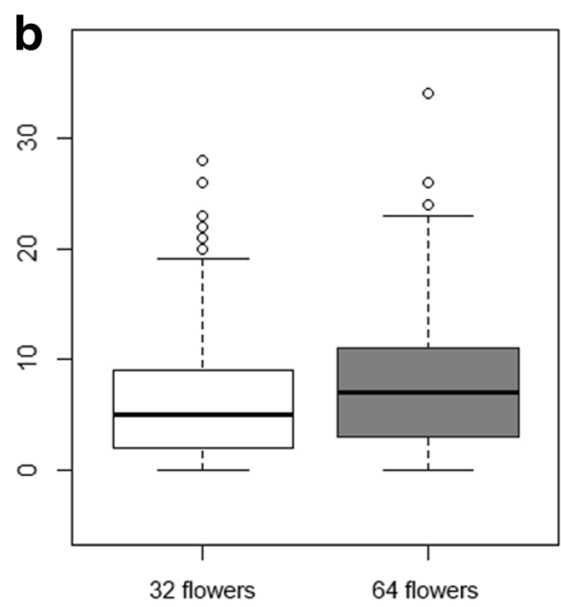

$\mathrm{HB}+\mathrm{BB}$ treatment side

Figure 2. Experiment 1: Number of bumble bee foragers from a BB only and $\mathbf{b} \mathrm{HB}+\mathrm{BB}$ side that visited artificial flowers when 32 or 64 flower arrays were available. No significant difference between treatments (GLMM PQL: $P=0.86$ ). Boxes represent range of data between the first and third quartiles around the median. Whiskers represent the remaining minimum and maximum with outliers.

bees and solitary species (Yokoi and Fujisaki 2011). Although our methods did not allow us to

Table I. Mean, standard deviation, and range of bumble bee and honey bee counts under different treatment conditions for each glasshouse side during all of experiments 1 and 2

\begin{tabular}{lllll}
\hline Side & Treatment & Mean & SD & Range \\
\hline
\end{tabular}

Experiment 1

Bumble bee forager counts

$\begin{array}{lllll}\text { BB } & 32 \text { flowers } & 8.2 & 5.6 & 0-23 \\ \text { BB } & 64 \text { flowers } & 10 & 5.3 & 0-26 \\ \text { HB+BB } & 32 \text { flowers } & 6.7 & 5.8 & 0-28 \\ \text { HB+BB } & 64 \text { flowers } & 9.3 & 5.6 & 0-34\end{array}$

Honey bee forager counts

$\begin{array}{lllll}\text { HB+BB } & 32 \text { flowers } & 11.4 & 8.4 & 0-34 \\ \text { HB+BB } & 64 \text { flowers } & 19.9 & 12.7 & 0-48\end{array}$

Experiment 2

Bumble bee forager counts

$\begin{array}{lllll}\text { BB } & 2-M & 8.3 & 4.1 & 0-27 \\ \text { BB } & 4-M & 9.7 & 7.6 & 0-47 \\ \text { HB+BB } & 2-M & 6 & 3.1 & 0-17 \\ \text { HB+BB } & 4-M & 8.8 & 6.2 & 0-28\end{array}$

Honey bee forager counts

$\begin{array}{lllll}\mathrm{HB}+\mathrm{BB} & 2-\mathrm{M} & 12 & 10.3 & 0-41 \\ \mathrm{HB}+\mathrm{BB} & 4-\mathrm{M} & 13 & 10.7 & 0-44\end{array}$

observe direct behavioral interactions, there was no evidence that honey bee presence had a negative effect on bumble bees. On the contrary, we often found the two species feeding together on the same flowers, a phenomenon that increased as the number of foragers engaged in the floral arrays increased. This sharing behavior was observed although resources available in the artificial floral arrays were never fully utilized. In nature, bees may share relatively large flowers or inflorescences (e.g., Asteraceae) without conflict (personal observation). Moreover, in resource-limiting environments, $B$. terrestris foragers will physically displace conspecifics from artificial flowers (Lihoreau et al. 2016). The abundance of nectar and relatively low degree of floral usage in our study suggests that competition between bees was relatively limited, leading to less displacement than was previously exhibited under artificial conditions (Pasquaretta et al. 2019; Lihoreau et al. 2016; Rogers et al. 2013). It is also possible that bees in our study began associating the presence of other individuals with sucrose rewards (Avarguès-Weber et al. 2018; Avarguès-Weber and Chittka 2014).

After removing half of the food source, honey bee foraging decreased, but bumble bee foraging was not affected by the reduction in honey bee foragers. Bumble bees do not, however, provide 


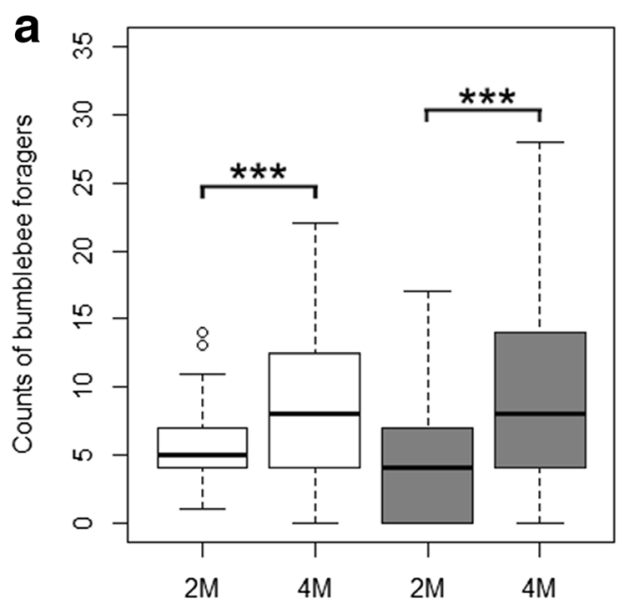

Resource quality

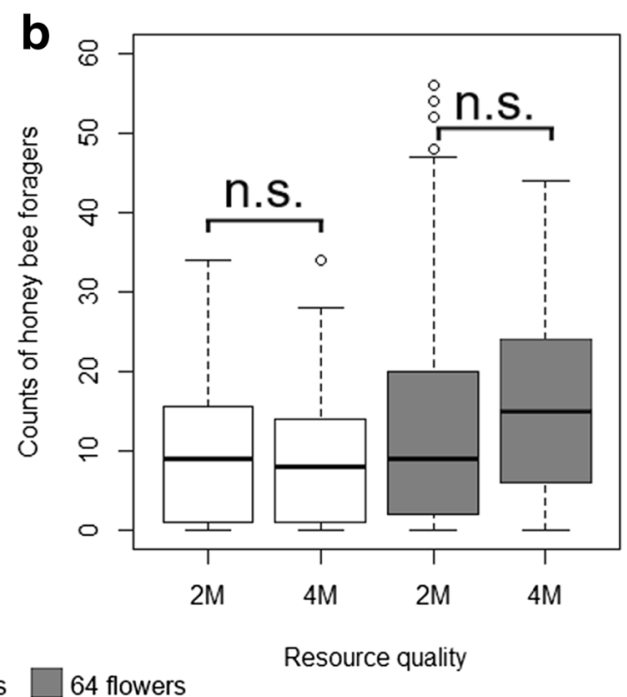

Figure 3. Experiment 2: Boxplots of bumble bee and honey bee forager counts per 32/64 flower treatments and 2$\mathrm{M} / 4-\mathrm{M}$ sugar concentration combinations by sides a $\mathrm{BB}$ only and $\mathbf{b} \mathrm{HB}+\mathrm{BB}$. Asterisks denote significant values (GLMM PQL: a $P=0.002$; b $P=0.27$ ) between treatments. Boxes represent range of data between the first and third quartiles around the median. Whiskers represent the remaining minimum and maximum with outliers.

directional information (Dornhaus and Chittka 2001). That said, bumble bees forage over shorter distances than honey bees, which may make directional information, particularly in environments such as the one used in this study, less relevant (Goulson 2003b). When resources are less than $100 \mathrm{~m}$ from the hive, honey bees can recruit others with a round dance, a method similar to bumble bee recruitment where foragers motivated nestmates, but distance or direction is not communicated (Gardner et al. 2008). When resources were reduced, there may have been insufficient feedback in the honey bee hive to elicit effective recruitment to the remaining local resources. Therefore, the behavioral response by honey bees to reduce overall foraging effort when resources are reduced, and to overlook spatially heterogenous high-quality resources, may be related to their colony-level foraging behavior. The more individualistic foraging behavior of bumble bees and the propensity for individuals to sample and select for higher quality resources at a local level may explain the differences in response (Nakamura and Kudo 2016).

In our study, honey bee foragers did not stop foraging at the food source they had become accustomed to when a higher quality resource was introduced at close range. Both honey bees and bumble bees are able to learn similar behaviors and associate them with floral rewards (Stöbbe et al. 2015), but in this case there was a marked difference in behaviors for both experiments on floral choice. These results support conclusions that highlight differences in competitive potential depending on the distribution and quality of resources across the landscape (Herbertsson et al. 2016).

In a controlled environment, we found no evidence that bumble bees were affected by the presence of honey bees regardless of whether the quantity or quality of food was manipulated. $B$. terrestris individuals have been observed discriminating and preferring higher quality resources in field trials (Ruedenauer et al. 2015, 2016). Likewise in laboratory studies, bumble bees prefer higher concentrations and quality of both pollen and nectar (Konzmann and Lunau 2014). This response might be because they often rely on their own experiences when rewards are constant (Dunlap et al. 2016; Dawson and Chittka 2014), whereas honey bees are directed by communication among nestmates when leaving the colony. The results from our study can help us to understand how both species have seemingly 
coexisted well in New Zealand since their introduction in the nineteenth century. A follow-up to this study might test the interaction of these bee species when a third pollinator is introduced. Unfortunately, native New Zealand bees are relatively difficult to rear in captivity, but other bee species could be used elsewhere. Understanding how overlapping sympatric pollinator guilds cope with the presence of one another is an important step in determining competitive potential.

\section{CONCLUSIONS}

The results of these experiments support differences in foraging behaviors and give insight into the strategies that honey bees and bumble bees may utilize under different resource conditions. Resources used by both bee species often overlapped, but potential competition between honey bees and bumble bees may be mitigated by the respective physiological and social adaptations that allow for temporal resource partitioning and flexibility in resource selection. The presence of honey bees did not interfere with bumble bees utilizing resources and the bee species foraged together without interference when resources were abundant. However, reducing the number of available flowers had the unforeseen result of reducing honey bee foragers, as opposed to increasing competition.

The primary limitations of this study were availability of resources and the difficulty of accommodating honey bees within an enclosed space despite the large dimensions of the glasshouse used. Honey bee hives confined in glasshouses generally do not forage well, showing reductions in larval and pupal production compared with when they are able to forage naturally (Sabara and Winston 2003). As a result, the number of potential combinations of flower numbers, resource types and density (nectar and pollen), ratios and combinations of bees, and replicates were constrained.

Overall, it is likely that bumble bees have a biological edge in foraging under confined conditions as compared with honey bees. The results from this glasshouse study may be most ecologically relevant to habitats where both honey bees and bumble bees forage, and potentially highlight foraging strategies that may allow some resilience in the provision of pollination services.

\section{ACKNOWLEDGMENTS}

We thank the Division of Sciences for PhD support and also the Departments of Botany and Zoology at the University of Otago and Diane Barton and Bruce Philip at AgResearch Invermay for logistical support.

\section{AUTHORS' CONTRIBUTION}

JMI, ARM, BIPB, KJMD, and JML conceived and designed experiments, interpreted results. TWDJ assisted with data analyses. JMI wrote the paper. BIPB, KJMD, JML, and JMJ participated with the final manuscript.

\section{Funding information}

This study was financially supported by the University of Otago through an Otago Research Grant.

Les abeilles mellifères ne déplacent pas les bourdons butinant sur des fleurs artificielles riches en nectar.

abeille mellifère / bourdon / fleur artificielle / butiner / compétition.

\section{Honigbienen verdrängen keine sammelnden Hummeln auf nektarreichen Blüten.}

\section{Honigbiene / Hummel / künstliche Blüten / Sammelverhalten / Konkurrenz.}

\section{REFERENCES}

Anon (2013) R: a language and environment for statistical computing. Version 3.2.3.

Avarguès-Weber A. \& Chittka L. (2014) Observational conditioning in flower choice copying by bumblebees (Bombus terrestris): influence of observer distance and demonstrator movement. PLoS One 9 , e88415.

Avarguès-Weber A., Lachlan R. \& Chittka L. (2018) Bumblebee social learning can lead to suboptimal 
foraging choices. Anim. Behav. doi: https://doi. org/10.1016/j.anbehav.2017.11.022.

Balfour N. J., Gandy S. \& Ratnieks F. L. W. (2015) Exploitative competition alters bee foraging and flower choice. Behav. Ecol. Sociobiol. 69 , 1731-1738.

Bates D., Maechler M. \& Bolker B. M. (2013) lme4: Linear mixed-effects models using S4 classes. $R$ Packag. version 0.999999-2.

Dawson E. H. \& Chittka L. (2014) Bumblebees (Bombus terrestris) use social information as an indicator of safety in dangerous environments. Proc. R. Soc. B Biol. Sci. 281 .

Donovan B. J. (1980) Interactions between native and introduced bees in New Zealand. N. Z. J. Ecol. 3 , 104-116.

Dornhaus A. \& Chittka L. (2001) Food alert in bumblebees (Bombus terrestris): possible mechanisms and evolutionary implications. Behav. Ecol. Sociobiol. 50 , 570 576.

Dornhaus A. \& Couvillon M. (2010) Small worker bumble bees (Bombus impatiens) are hardier against starvation than their larger sisters. Insectes Soc. doi: https://doi. org/10.1007/s00040-010-0064-7.

Dunlap A. S., Nielsen M. E., Dornhaus A. et al. (2016) Foraging Bumble Bees Weigh the Reliability of Personal and Social Information. Curr. Biol. 26, 1195-1199.

Dupont Y. L., Hansen D. M., Valido A. \& Olesen J. M. (2004) Impact of introduced honey bees on native pollination interactions of the endemic Echium wildpretii (Boraginaceae) on Tenerife, Canary Islands. Biol. Conserv. 118 , 301-311.

Eickwort G. C. \& Ginsberg H. S. (1980) Foraging and mating behavior in Apoidea. Anпu. Rev. Entomol. 25 , 421-446.

Gardner K. E., Seeley T. D. \& Calderone N. W. (2008) Do honeybees have two discrete dances to advertise food sources? Anim. Behav. 75 , 1291-1300.

Garibaldi, L. A., Requier, F., Rollin, O., Andersson, G. K., (2017) Towards an integrated species and habitat management of crop pollination. Curr. Opin. Insect Sci. 21, 105-114. https://doi.org/10.1016/j.cois.2017.05.016.

Goulson D. (2003a) Effects of introduced bees on native ecosystems. Annu. Rev. Ecol. Evol. Syst. 34 , 1-26.

Goulson D. (2003b) Bumblebees: Their Behaviour and Ecology. Oxford University Press, Oxford.

Goulson D. (2010) Impacts of non-native bumblebees in Western Europe and North America. Appl. Entomol. Zool. $45,7-12$.

Goulson D. \& Sparrow K. (2009) Evidence for competition between honeybees and bumblebees; effects on bumblebee worker size. J. Insect Conserv. $13,177-181$.

Heinrich B. (1976) The foraging specializations of individual bumblebees. Ecol. Monogr. 46, 105-128.

Herbertsson L., Lindström S. A. M., Bommarco R. \& Smith H. G. (2016) Competition between managed honeybees and wild bumblebees depends on landscape context. Basic Appl. Ecol. doi: https://doi.org/10.1016 /j.baae.2016.05.001.

Hingston A. B. \& McQuillan P. B. (1999) Displacement of Tasmanian native megachilid bees by the recently introduced bumblebee Bombus terrestris (Linnaeus, 1758)(Hymenoptera: Apidae). Aust. J. Zool.

Howlett B. G. \& Donovan B. (2010) A review of New Zealand's deliberately introduced bee fauna: current status and potential impacts. New Zeal. Entomol.

Huryn V. M. B. (1997) Ecological impacts of introduced honey bees. Q. Rev. Biol. 72 , 275-297.

Inoue M. N., Yokoyama J. \& Washitani I. (2008) Displacement of Japanese native bumblebees by the recently introduced Bombus terrestris (L.) (Hymenoptera: Apidae). J. Insect Conserv. 12 , 135-146.

Konzmann S. \& Lunau K. (2014) Divergent rules for pollen and nectar foraging bumblebees-a laboratory study with artificial flowers offering diluted nectar substitute and pollen surrogate. PLoS One 9 , e91900.

Lihoreau M., Chittka L. \& Raine N. E. (2016) Monitoring Flower Visitation Networks and Interactions between Pairs of Bumble Bees in a Large Outdoor Flight Cage. PLoS One $11,1-21$.

Nakamura S. \& Kudo G. (2016) Foraging responses of bumble bees to rewardless floral patches: importance of within-plant variance in nectar presentation. AoB Plants doi: https://doi.org/10.1093 /aobpla/plw037.

Paini D. R. (2004) Impact of the introduced honey bee (Apis mellifera) (Hymenoptera: Apidae) on native bees: A review. Austral Ecol. 29 , 399-407.

Paini D. R. \& Roberts J. D. (2005) Commercial honey bees (Apis mellifera) reduce the fecundity of an Australian native bee (Hylaeus alcyoneus). Biol. Conserv. 123 , 103-112.

Pasquaretta C., Jeanson R., Pansanel J., Raine N. E., Chittka L. \& Lihoreau M. (2019) A spatial network analysis of resource partitioning between bumblebees foraging on artificial flowers in a flight cage. Mov. Ecol. 7, 1-10.

Rogers S. R., Cajamarca P., Tarpy D. R. et al. (2013) Honey bees and bumble bees respond differently to inter- and intra-specific encounters. Apidologie 44, 621-629.

Roubik D. W. (1978) Competitive interactions between neotropical pollinators and Africanized honey bees. Science (80-. ). 201 , 1030-1032.

Roubik D. W. \& Wolda H. (2001) Do competing honey bees matter? Dynamics and abundance of native bees before and after honey bee invasion. Popul. Ecol. 43, 53-62.

Roubik D. W., Moreno J. E., Vergara C. \& Wittmann D. (1986) Sporadic food competition with the African honey bee: Projected impact on neotropical social bees. J. Trop. Ecol. 2 , 97-111.

Ruedenauer F. A., Spaethe J. \& Leonhardt S. D. (2015) How to know which food is good for you: bumblebees 
use taste to discriminate between different concentrations of food differing in nutrient content. J. Exp. Biol. doi: https://doi.org/10.1242/jeb.118554.

Ruedenauer F. A., Spaethe J. \& Leonhardt S. D. (2016) Hungry for quality - individual bumblebees forage flexibly to collect high-quality pollen. Behav. Ecol. Sociobiol. 70 , 1209-1217.

Sabara H. A. \& Winston M. L. (2003) Managing Honey Bees (Hymenoptera : Apidae) for Greenhouse Tomato Pollination. J. Econ. Entomol. 96 , 547-554.

Schaffer W., Jensen D. \& Hobbs D. (1979) Competition, foraging energetics, and the cost of sociality in three species of bees. Ecology 60 , 976-987.

Schaffer W., Zeh D. \& Buchmann S. (1983) Competition for nectar between introduced honey bees and native North American bees and ants. Ecology 64 , 564-577.

Seeley T. D., Camazine S. \& Sneyd J. (1991) Collective decision-making in honey bees: how colonies choose among nectar sources. Behav. Ecol. Sociobiol. 28 , 277-290.

Spaethe J. \& Weidenmüller A. (2002) Size variation and foraging rate in bumblebees (Bombus terrestris). Insectes Soc.

Stöbbe J., Schramme J. \& Claßen-Bockhoff R. (2015) Training experiments with Bombus terrestris and Apis mellifera on artificial 'Salviá flowers. Flora Morphol. Distrib. Funct. Ecol. Plants doi: https://oi. org/10.1016/j.flora.2015.12.007.

Thomson D. (2004) Competitive interactions between the invasive European honey bee and native bumble bees. Ecology 85 , 458-470.
Thomson D. M. (2006) Detecting the effects of introduced species: a case study of competition between Apis and Bombus. Oikos 114, 407-418.

Thomson D. M. (2016) Local bumble bee decline linked to recovery of honey bees, drought effects on floral resources. Ecol. Lett. doi: https://doi.org/10.1111 /ele.12659.

von Frisch K. (1967) The dance language and orientation of bees. Heredity (Edinb). $90,212$.

Walther-Hellwig K., Fokul G., Frankl R., Buchler R., Klemens E. \& Volkmar W. (2006) Increased density of honeybee colonies affects foraging bumblebees. Apidologie 37 , 517-532.

Wedderburn R. W. M. (1974) Quasi-likelihood functions, generalized linear models, and the Gauss-Newton method. Biometrika 61, 439-447.

Westphal C., Steffan-Dewenter I. \& Tscharntke T. (2006) Bumblebees experience landscapes at different spatial scales: possible implications for coexistence. Oecologia 149 , 289-300.

Wood S. N. (2011) Fast stable restricted maximum likelihood and marginal likelihood estimation of semiparametric generalized linear models. J. R. Stat. Soc. B. 73, 3-36.

Yokoi T. \& Fujisaki K. (2011) To forage or not: Responses of bees to the presence of other bees on flowers. Ann. Entomol. Soc. Am. 104 , 353-357.

Publisher's note Springer Nature remains neutral with regard to jurisdictional claims in published maps and institutional affiliations. 